\title{
RETROFITTING OF DANUBE VESSELS FOR A GREEN AND EFFICIENT FLEET
}

\author{
Angheluță Cristi-Marian \\ Ship Design Group, \\ 1A Luminoasa Street, 807325, Galati, Romania, \\ E-mail: cristi.angheluta@ shipdesigngroup.eu
}

\author{
Perijoc Dumitru-Silviu \\ Ship Design Group, \\ 1A Luminoasa Street, 807325, Galati, Romania, \\ E-mail: silviu.perijoc@ shipdesigngroup.eu
}

\author{
Presură Adrian \\ Ship Design Group, \\ 1A Luminoasa Street, 807325, Galati, Romania, \\ E-mail: a.presura@shipdesigngroup.eu
}

\begin{abstract}
The following paper presents a research study based on the idea of reducing the environmental impact of inland waterway vessels by resorting to state-of-the-art technologies for treating the exhaust gases. The paper summarizes an analysis into the feasibility of retrofitting existing ships so as to comply with Stage $V$, the latest emission norms of the European Commission. Several types of river pushers were analyzed for the case study in order to reach a proper understanding of the implications of installing a new engine and after treatment system. The solutions proposed by engine manufacturers for compliance with the norms were analyzed and suitable engines were identified for the selected vessels, with the goal being to minimize the modifications required on-board. Based on the information obtained, a detailed analysis into the structural, piping, machinery, outfitting and electrical impact was made.
\end{abstract}

Keywords: inland vessels, green technologies, exhaust after treatment, stage V.

\section{INTRODUCTION}

Reducing the amount of emissions from vessels has been the de jure goal for regulatory bodies in the shipping industry for a while now, with the introduction of the EEDI coefficient and organizations such as IMO setting ambitious long-term goals [1]. For inland shipping, the European Parliament adopted in 2016 a set of regulations named Stage V [2], with the goal of reducing emissions. Certainly, this will also lead to a more modern inland shipping fleet by replacing outdated and deprecated engines and diesel generators with modern, safer and more efficient ones.
To push forward this initiative, the European Union set up a project called GRENDEL, as part of the Danube Transnational Programme, with the aim of modernizing the inland fleet and increasing its competitiveness.

There are many directions one could follow towards reducing the emissions of a vessel, ranging from improving performances by reducing drag up to treating the exhaust gases before being released into the atmosphere. The most common solutions are to act on the propulsion machinery, by improving the burning process, or by adding an after treatment system for the exhaust gases. 
Reducing the environmental footprint can thus be achieved by applying several solutions, such as [3]:

-Using an after-treatment system (with components including a particulate matter filter, a selective catalytic reducing unit or a diesel oxidation catalyst)

-Using an electronic drive management system

-Adopting another solution for the propulsion machinery (like diesel-electric or fuel cells)

-Using alternative combustion engines (such as those powered by LNG, a solution that is becoming more common)

-Using alternative fuels (such as hydrogen, biodiesel or biodiesel blend)

-Using high quality fuel (such as low sulphur fuel, a solution common for the marine shipping industry)

As partners in the project, the authors developed concept designs for retrofitting four inland pushers with stage $\mathrm{V}$ compliant technologies, more specifically, engines and after-treatment systems.

The principle of the technology is to employ a diesel particulate filter for the particulate matter and a selective catalytic reducer to chemically convert the nitrogen oxides into water and nitrogen. The issue was integrating the various proposals of the equipment manufacturers onboard the selected vessels.

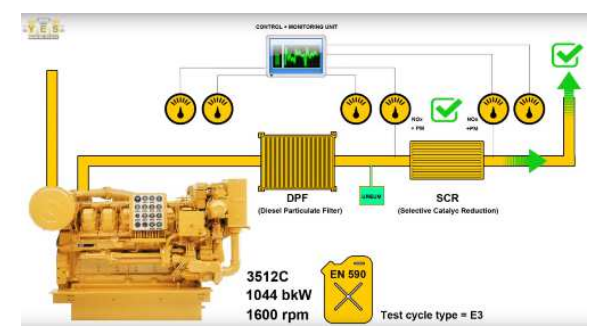

Fig.1 Caterpillar EATS schematic

Solutions for reducing emissions of propulsion machinery using the DPF technology are common in the automotive in- dustry, however, only recently manufacturers have found themselves in the position of having to adapt the technology for usage onboard vessel. One of the manufacturers that have taken on the challenge is Caterpillar.

Figure 1 above showcases the layout of an exhaust after treatment system proposed by Caterpillar. The exhaust gases first enter the Diesel Particulate Filter, in order to reduce the particulate matter content to acceptable levels. Some implementations also employ an afterburner, to purge the filters of impurities, so as to avoid replacing them at a set time interval. From the DPF the gases enter a mixing pipe, where urea is injected using compressed air. The mix then enters the Selective Catalytic Reduction (SCR) unit where the nitrogen oxides are converted to $\mathrm{H}_{2} \mathrm{O}$ and $\mathrm{N}_{2}$

Another solution comes from Mitsubishi, in the form a three-part sys-tem. More specifically, the system employs a mixing pipe, where the exhaust gases' temperature is raised using a burner unit and urea is injected, a converter unit containing the DPF and SCR, and a silencer.

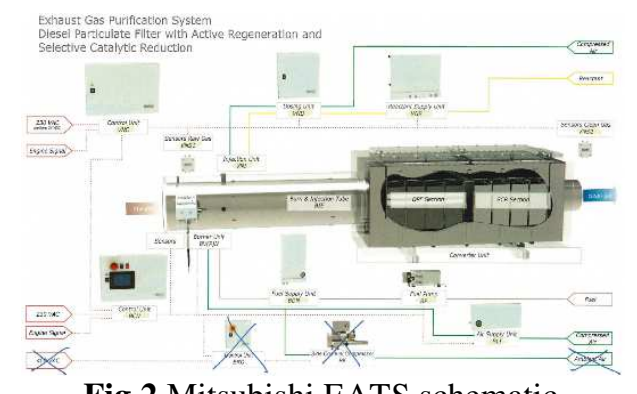

Fig.2 Mitsubishi EATS schematic

Finally, ABC have developed their own solution for complying with Stage V, in the form of a system containing first the $\mathrm{DPF}$, then the mixing pipe leading into an SCR unit containing two layers of SCR elements and an incorporated silencer. 


\section{RETROFITTING PHILOSOPHY TOWARDSSTAGE V COMPLIANCE}

The main criterion is performing the upgrade without altering the ship's operational profile. The most important restrictions when assessing the implementation strategy are posed by the vessel's hull geometry and machinery arrangement. Before proceeding towards the concept design, some initial factors need to be considered:

-The proposed vessel has to be prone and suited to retrofitting

-The vessel's performance and initial efficiency need to be assessed

-The most appropriate technology for retrofitting needs to be selected

-The feasibility of implementing the selected solution needs to be assessed

-The impact of the repowering on the vessel's performances needs to be determined

Three potential scenarios were identified when looking into repowering solutions for the analyzed vessels. The first one involves replacing only the engine with a new one, without other modifications. For that, the new engine should meet two criteria:

-the RPM of the new engine needs to be reasonably close to that of the old engine, more specifically, in a range of $\pm 2 \%$ from the initial RPM

-the output BHP of the new engine needs to be reasonably close to that of the old engine, more specifically, in a range of $-2 \%$ to $+10 \%$ from the initial BHP

This first solution would be the most cost effective and, as such, the desirable one.

The second solution would involve replacing both the engine and the gearbox. In this scenario, the new gearbox needs to have an output RPM similar to that of the initial system.

The third solution would involve replacing the engine, gearbox and propeller. This solution would be the least effective and has been overlooked for the design concepts studied.
For economic and emission calculations, the operational profile of a typical Danube pusher has been determined using statistical data. [4,5] An average of $60 \%$ MCR during a round-trip voyage was selected.

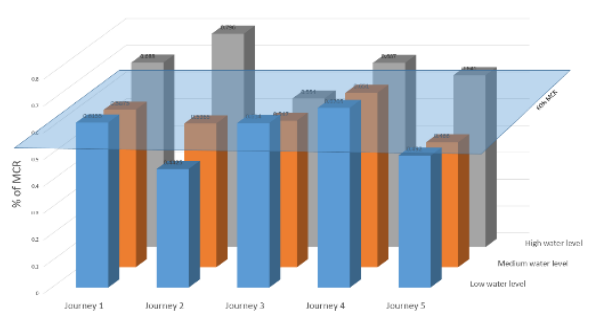

Fig.3 Danube pusher engine load factor

The vessels considered were selected by the ship owner, NAVROM, partner in the project. NAVROM is one of the largest inland waterway transport companies in Europe and the largest in Romania. They provide a variety of services, ranging from cargo and passenger transport up to shipbuilding and repairs. The vessels move over 10 million tons of cargo yearly, with a fleet containing push boats ranging between 800 to $3500 \mathrm{HP}$ and over 350 barges ranging from 1000 to $3000 \mathrm{t}$ deadweight. Based on the wear of the current engines, feasibility of performing the retrofit and several other factors, four vessel types were considered. More specifically, these are: -Type 1: 2 pushers with 2 x $1194 \mathrm{~kW} \mathrm{/}$ 1800 RPM engines

-Type 2: 4 pushers with 2 x $895 \mathrm{~kW} /$ 1800 RPM engines

-Type 3: 3 pushers with 2 x $1185 \mathrm{~kW} /$ 1000 RPM engines

-Type 4: 2 pushers with $2 \times 925 \mathrm{~kW} \mathrm{/}$ 750 RPM engines

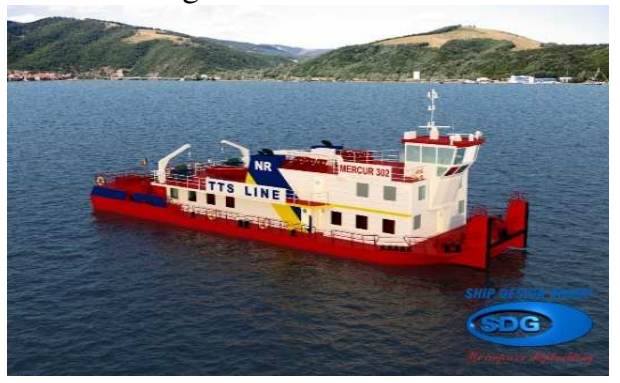

Fig.4 Typical Danube river pusher [6] 


\section{CONCEPT DESIGN FOR TYPE 1 PUSHER}

All of the four vessels studied are designed for voyages along the Danube, with typical barges ranging from 1000 to 3000 tons deadweight. The first vessel has the following main particulars:

Table 1. Type 1 main particulars

\begin{tabular}{|l|r|}
\hline Length over all & $34.60 \mathrm{~m}$ \\
\hline Length between perp. & $33.00 \mathrm{~m}$ \\
\hline Breadth moulded & $11.00 \mathrm{~m}$ \\
\hline Depth mid area & $2.80 \mathrm{~m}$ \\
\hline Depth aft area & $3.30 \mathrm{~m}$ \\
\hline Max. draught & $1.88 \mathrm{~m}$ \\
\hline Air draught & $8.80 \mathrm{~m}$ \\
\hline
\end{tabular}

The propulsion lines of all the vessels feature a fixed pitch ducted propeller, a shaft line, a reversing reduction gearbox and a main engine with a standard exhaust system [Fig.5, 10, 13, 16].

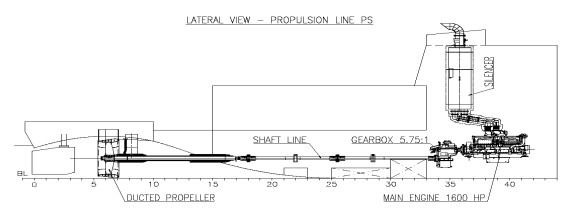

Fig.5 Type 1 pusher layout [6]

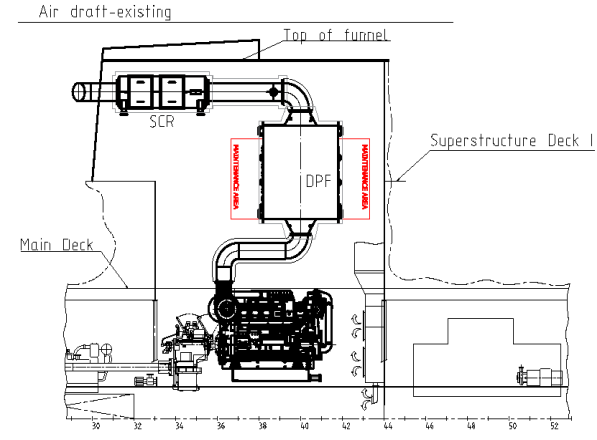

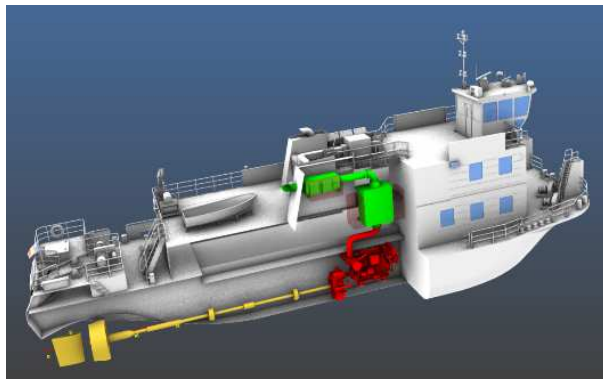

Fig.7 Caterpillar tech - 3D view -Type 1

With Caterpillar's technology, an engine-only replacement was selected as the most suitable solution, with Caterpillar's 3512C engine having the same RPM, power and dimensions as the original engine. The concept design is presented below.

A second proposal for retrofitting vessel 1 for compliance was received from Mitsubishi. With Mitsubishi's technology, the solution was to replace both the engine and the gearbox. The engine proposed is the Mitsubishi S16R (Z3)MPTAW with a MASSON MM W7400 gearbox to ensure the same output speed as the original propulsion system. The main differences between the two proposals is that Mitsubishi also employs a burner unit that raises the temperature of the exhaust gases, an Active Regeneration system that eliminates the need to replace filters and a separate silencer that can include a spark arrestor. The concept design is presented below.

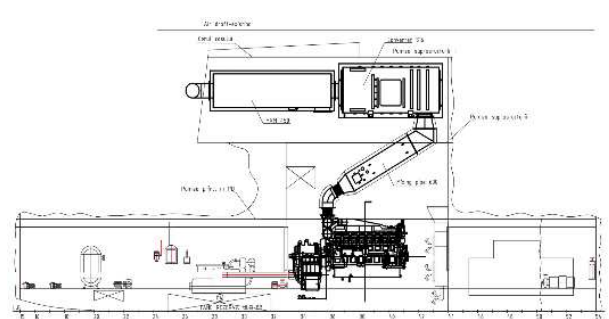

Fig.8 Type 1 vessel with Mitsubishi tech

Fig.6 Type 1 vessel with Caterpillar tech 


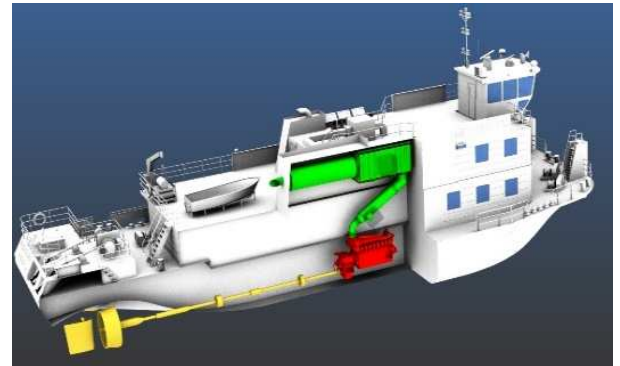

Fig.9 Mitsubishi tech - 3D View - Type 1

After assessing the current emissions of the first type of pusher, and comparing them with the limits imposed by Stage V, since the values of the new system are not provided at this point, a percentage reduction of emissions was evaluated and is presented below.

Table 2. Type 1 current engine emissions

\begin{tabular}{|c|c|c|c|}
\hline & Actual & $\begin{array}{l}\text { Stage I } \\
\text { limits }\end{array}$ & $\begin{array}{l}\text { Emissions } \\
\text { per } 1 \\
\text { ship/year }\end{array}$ \\
\hline & \multicolumn{2}{|c|}{$\mathrm{g} / \mathrm{kWh}$} & tons \\
\hline $\mathrm{HC}$ & 0.25 & 1.30 & 1.79 \\
\hline NOx & 8.89 & 9.20 & 63.69 \\
\hline $\mathrm{PM}$ & N.A. & 0.85 & 6.09 \\
\hline
\end{tabular}

Table 3. Maximum engine emissions

\begin{tabular}{|l|c|c|}
\hline \multirow{2}{*}{} & Stage V limits & $\begin{array}{l}\text { Emission per } \\
\text { 1 ship/year }\end{array}$ \\
\cline { 2 - 3 } & $\mathrm{g} / \mathrm{kWh}$ & tons \\
\hline $\mathrm{HC}$ & 0.19 & 1.34 \\
\hline NOx & 1.80 & 12.68 \\
\hline PM & 0.015 & 0.11 \\
\hline
\end{tabular}

Table 4. Type 1 emission reduction

\begin{tabular}{|l|c|c|}
\hline \multirow{2}{*}{} & $\begin{array}{l}\text { Emission } \\
\text { reduction }\end{array}$ & $\begin{array}{l}\text { Emission re- } \\
\text { duction per 1 } \\
\text { ship/year }\end{array}$ \\
\cline { 2 - 3 } & $\%$ & tons \\
\hline HC & $\mathbf{2 5}$ & $\mathbf{0 . 4 5}$ \\
\hline NOx & $\mathbf{8 0}$ & $\mathbf{5 1 . 0 1}$ \\
\hline PM & $\mathbf{9 7}$ & $\mathbf{5 . 9 3}$ \\
\hline
\end{tabular}

\section{CONCEPT DESIGN FOR VES- SELS TYPE 2, 3 AND 4}

The second vessel has the following main particulars:

Table 5. Type 2 main particulars

\begin{tabular}{|l|r|}
\hline Length over all & $34.60 \mathrm{~m}$ \\
\hline Length between perp. & $33.00 \mathrm{~m}$ \\
\hline Breadth moulded & $10.10 \mathrm{~m}$ \\
\hline Depth mid area & $2.65 \mathrm{~m}$ \\
\hline Depth aft area & $3.30 \mathrm{~m}$ \\
\hline Max. draught & $1.68 \mathrm{~m}$ \\
\hline Air draught & $8.80 \mathrm{~m}$ \\
\hline
\end{tabular}

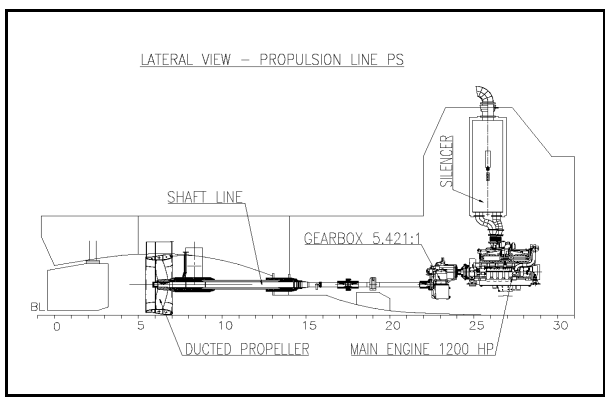

Fig.10 Type 2 pusher layout [6]

With Caterpillar's technology, an engine-only replacement was selected as the most suitable solution, with Caterpillar's C32 SCAC engine having the same RPM, power and dimensions as the original engine. The concept design is presented below.

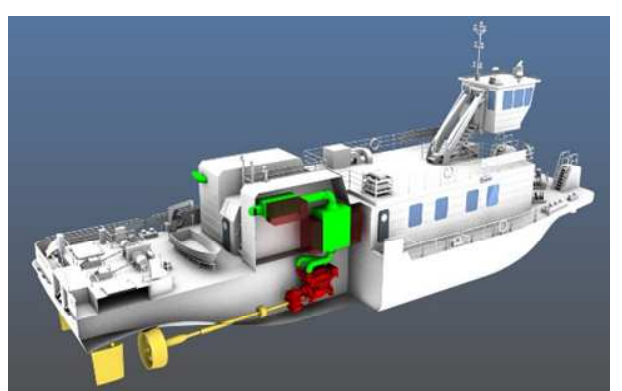

Fig.11 Caterpillar tech - 3D View -Type 2 
With Mitsubishi's technology, the solution was to replace both the engine and the gearbox. The engine proposed is the Mitsubishi S12R (Z3)MPTAW with a MASSON MM W7200 gearbox to ensure the same output speed as the original propulsion system.'

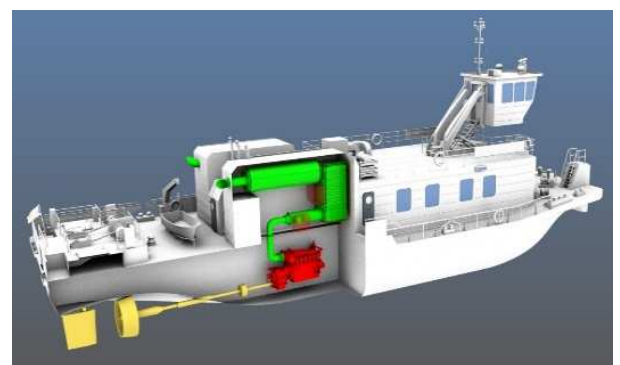

Fig.12 Mitsubishi tech - 3D View -Type 2

The third vessel has the following main particulars:

Table 6. Type 3 main particulars

\begin{tabular}{|l|r|}
\hline Length over all & $32.00 \mathrm{~m}$ \\
\hline Breadth moulded & $11.40 \mathrm{~m}$ \\
\hline Depth & $3.00 \mathrm{~m}$ \\
\hline Max. draught & $1.80 \mathrm{~m}$ \\
\hline
\end{tabular}

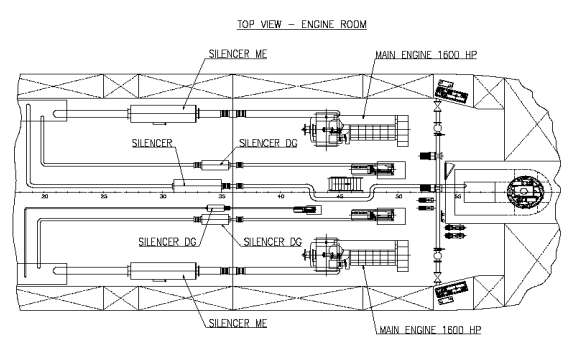

Fig.13 Type 3 pusher layout [6]

A first proposal comes from Caterpillar, in the form of replacing both the engine and the gearbox. The proposed engine is model Caterpillar 3512C @ $1174 \mathrm{~kW}$ and 1800 RPM. The concept design is presented below.

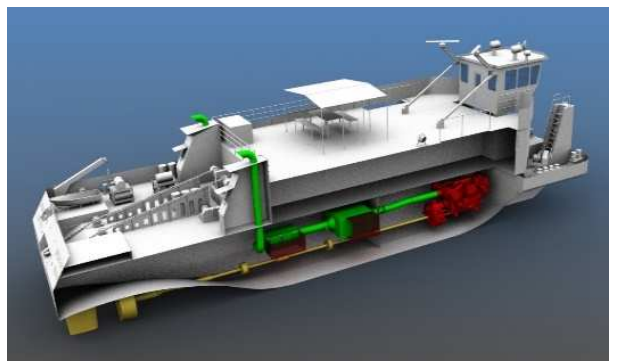

Fig.14 Caterpillar tech - 3D Model

With Mitsubishi's technology, the solution was to replace both the engine and the gearbox. The engine proposed is the Mitsubishi S16R (Z3)MPTAW with a MASSON MM W7400 gearbox to ensure the same output speed as the original propulsion system. The concept design is presented below.

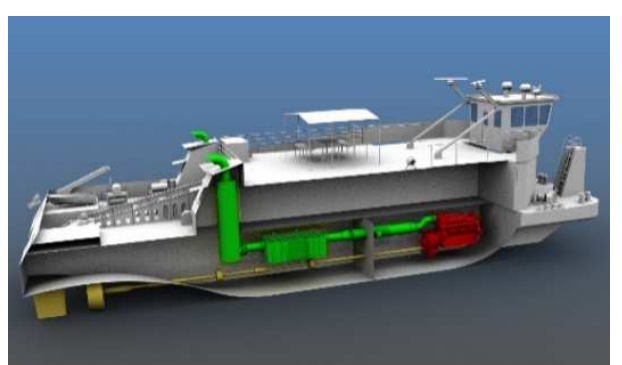

Fig.15 Mitsubishi tech - 3D view -Type 3

The fourth vessel has the following main particulars:

Table 7. Type 4 main particulars

\begin{tabular}{|l|r|}
\hline Length over all & $34.66 \mathrm{~m}$ \\
\hline Length between perp. & $33.00 \mathrm{~m}$ \\
\hline Breadth moulded & $10.10 \mathrm{~m}$ \\
\hline Depth mid area & $2.65 \mathrm{~m}$ \\
\hline Depth aft area & $3.30 \mathrm{~m}$ \\
\hline Max. draught & $1.68 \mathrm{~m}$ \\
\hline Air draught & $5.17 \mathrm{~m}$ \\
\hline
\end{tabular}




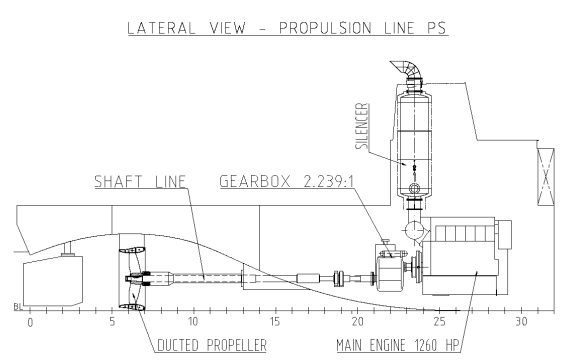

Fig.16 Type 4 pusher layout [6]

A first proposal for the fourth pusher type is with technology from Mitsubishi, more specifically, replacing the main engine with a Mitsubishi S12R (Z3)MPTAW and the gearbox with a MASSON MM W7200. The concept design is presented below.

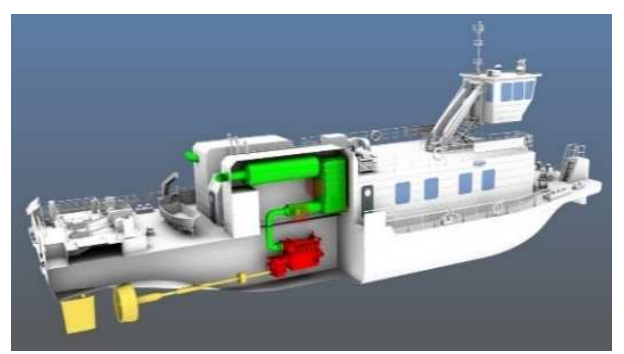

Fig.17 Mitsubishi tech - 3D view -Type 4

With ABC's technology, the solution was to replace the engine with an $\mathbf{A B C}$ 6DZC-750-155. The concept design is presented below.

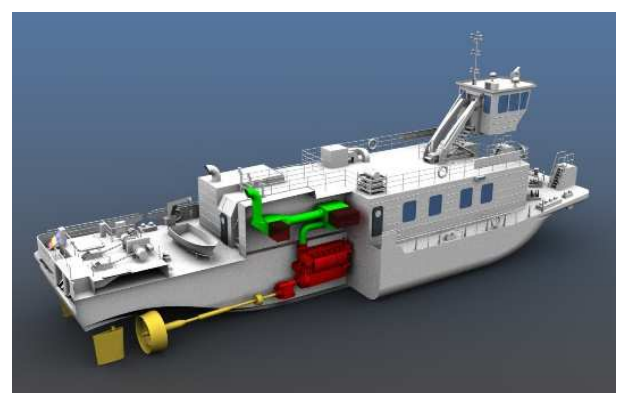

Fig.18 ABC tech - 3D view -Type 4

\section{OVERALL IMPACT AND CONCLUSIONS}

The modifications needed to accommodate the new equipment are as follows:

-A new main engine foundation and modifications to the existing structure

-New supports for the new exhaust system -Modifications to the steel structure of the funnels

-A new urea tank

-A new exhaust system

-Modifications of the diesel generators' exhaust system

-New box coolers and cooling piping

-Changes to some piping systems serving the engines

-Engine room ventilation modifications -New urea and compressed air systems -Main switchboard modifications and related cabling and panels

Certainly, the modifications purported by the retrofitting design concepts seem problematic, but the cost is lower when compared to that of a new-build. There are, however, a few disadvantages too, such as the increased maintenance and running costs of the new system, as well as a reduced availability of replacement parts. For vessels with a crowded engine room arrangement, merging of an after-treatment solution might be completely impractical. The economic cost is also influenced by the extra cost of replenishing the urea system.

Once the retrofit is done, the vessel will have to undergo some trials to ensure proper functioning of the new equipment and to asses performance and emission levels modifications.

An analysis on the emission reduction for vessels type 2,3 , and 4 is presented below. 
Table 8. Type 2 emission reduction

\begin{tabular}{|l|c|c|}
\hline \multirow{2}{*}{} & $\begin{array}{l}\text { Emission } \\
\text { reduction }\end{array}$ & $\begin{array}{l}\text { Emission re- } \\
\text { duction per 1 } \\
\text { ship/year }\end{array}$ \\
\cline { 2 - 3 } & $\%$ & tons \\
\hline HC & $\mathbf{5}$ & $\mathbf{0 . 0 5}$ \\
\hline NOx & $\mathbf{7 9}$ & $\mathbf{3 6 . 0 3}$ \\
\hline PM & $\mathbf{9 8}$ & $\mathbf{4 . 4 9}$ \\
\hline
\end{tabular}

Table 9. Type 3 emission reduction

\begin{tabular}{|l|c|c|}
\hline & $\begin{array}{l}\text { Emission } \\
\text { reduction }\end{array}$ & $\begin{array}{l}\text { Emission re- } \\
\text { duction per 1 } \\
\text { ship/year }\end{array}$ \\
\cline { 2 - 3 } & $\%$ & tons \\
\hline HC & $\mathbf{8 5}$ & $\mathbf{7 . 8 9}$ \\
\hline NOx & $\mathbf{8 0}$ & $\mathbf{5 2 . 6 1}$ \\
\hline PM & $\mathbf{9 8}$ & $\mathbf{5 . 9 3}$ \\
\hline
\end{tabular}

Table 10. Type 4 emission reduction

\begin{tabular}{|l|c|c|}
\hline \multirow{2}{*}{} & $\begin{array}{l}\text { Emission } \\
\text { reduction }\end{array}$ & $\begin{array}{l}\text { Emission re- } \\
\text { duction per 1 } \\
\text { ship/year }\end{array}$ \\
\cline { 2 - 3 } & $\%$ & tons \\
\hline HC & $\mathbf{8 5}$ & $\mathbf{6 . 1 6}$ \\
\hline NOx & $\mathbf{8 0}$ & $\mathbf{4 1 . 0 7}$ \\
\hline PM & $\mathbf{9 8}$ & $\mathbf{4 . 6 4}$ \\
\hline
\end{tabular}

Table 11. Total reduction for all vessels

\begin{tabular}{|c|c|c|c|}
\hline Vessel & $\begin{array}{l}\text { Total } \\
\text { reduction } \\
\text { HC }\end{array}$ & $\begin{array}{l}\text { Total } \\
\text { reduction } \\
\text { NOx }\end{array}$ & $\begin{array}{l}\text { Total } \\
\text { reduction } \\
\text { PM }\end{array}$ \\
\hline & \multicolumn{3}{|c|}{ tons } \\
\hline Type 1 & 0.90 & 102.02 & 11.96 \\
\hline Type 2 & 0.20 & 144.12 & 17.96 \\
\hline Type 3 & 23.67 & 157.83 & 17.79 \\
\hline Type 4 & 12.32 & 82.14 & 9.28 \\
\hline $\begin{array}{l}\text { Total } \\
\text { for all } \\
\text { vessels }\end{array}$ & 37.09 & 486.11 & 56.99 \\
\hline
\end{tabular}

Performance-improving technologies and retrofit solutions are constantly evolving, both due to regulations and due to economic drive. Currently, implementing an after treatment system is a feasible solution for inland vessels, but the design in- volves different approaches for each vessel and situation.

An analysis on the reduction of emissions, in tons per year, for the entire set of vessels was made. The results are presented below.

\section{ACKNOWLEDGEMENTS}

The present paper has been developed with the support of Ship Design Group Galați, within the Project GRENDEL Green and efficient Danube fleet, Danube Transnational Programme of the European Union (01.06.2018-30.11.2020).

\section{REFERENCES}

[1]. International Maritime Organization Resolution MEPC.304(72), Initial IMO strategy on reduction of GHG emissions from ships, 2018

[2]. NRMM STAGE V REGULATION (EU) 2016/1628 (Emission regulation for nonroad mobile machinery: EU Stage V)

[3]. Schweighofer J Blaaw H G Smyth M D 2008 How to Improve the Environmental Performance of Inland Navigation, The 30th Motorship Propulsion and Emissions Conference 2008 Gothenburg, 20th -22 nd May, 2008

[4]. www.prominent-iwt.eu, accessed on 26.11.2019 at $13: 25$

[5]. D1.1 List of operational profiles and fleet families, Prominent, European Commission

[6]. Courtesy of Compania de Navigatie Fluviala Romana NAVROM S.A. Galati

[7]. GRENDEL - Green and efficient Danube fleet, Danube Transnational Programme of the European Union (http://www.interreg-danube.eu, accessed on 10.04.2019, 13:40)

Paper received on November $11^{\text {th }}, 2019$ 